Article

\title{
Strategies of Managing Coach Driver Job Stress for Sustainable Coach Tourism Industry-The Use of DANP-V Model
}

\author{
Chui-Hua Liu \\ Department of Tourism \& Hospitality, Kainan University, Taoyuan City 33857, Taiwan; \\ liu32lee@mail.knu.edu.tw; Tel.: +886-988-235-653
}

Received: 3 April 2020; Accepted: 27 April 2020; Published: 2 May 2020

\begin{abstract}
Coach drivers are integral to the coach tourism industry. However, they are susceptible to job stress in the tourism context. Few studies address this problem from a job stress theory and tourism scenario. This study, thus, examines the network relationships between criteria and proposes a physical and workable improvement plan. A novel DEMATEL-based ANP and VIKOR (DANP-V) model is used to examine the job stress criteria based on the transaction stress framework in the tourist coach context of Taiwan. The expert survey produced useful results. The influential network relation map (INRM) illustrates the sequence of improvement is job stressors, cognitive coping strategies, and stress outcomes. The gap values of the modified VIKOR suggest the first priority to reach the aspired level is reducing stress outcomes. However, teaching active action as a strategy to cope with job stress is a long-term goal. These results are formulated into an action plan and can be easily indexed and followed. The findings have practical implications for decision-makers and coach drivers and may contribute to coach driver job-related stress management, ultimately, helping the sustainability of coach tourism.
\end{abstract}

Keywords: coach driver; DANP-V model; sustainable coach tourism

\section{Introduction}

Coach drivers are the soul of the coach tourism industry. They are significant and responsible for the safety of coach tour travelers [1-3], thus, crucial to sustainable coach tourism. Nevertheless, coach drivers have been accused of being responsible for a series of deadly accidents in Taiwan. These fatal driver-made accidents had a great impact on the coach tourism industry. It has been reported that the fatal accidents occurred as a result of human error, most notably, driving while fatigued, rushing to the next stop, or altered mental status $[1,4,5]$ (see Table 1 ). The existing literature indicates that job stress may affect an individual's overall well-being and possibly makes an individual exhausted, causing errors in daily life and work [6,7].

The issue has drawn the attention of Taiwanese governments. Improvements are rapidly implemented but mainly involve the modification of regulations (e.g., limiting driving hours, implementing bus safety checklists, instituting on-the-road training) in the aftermath. However, the mental state of drivers cannot be regulated. In the competitive travel-transportation field of coach tourism, coach drivers are far more commercially sensitive and susceptible to job stress than common professional drivers [1,4]. To prevent coach accidents, job stress cannot be neglected. Particularly, "how" job stress is perceived and addressed by the drivers. From the transaction stress perspective, the causes of stress, cognitive coping appraisal, and stress outcomes are parts of a constant relational process [8]. Cognition will influence whether a person will experience a situation as stressful [7]. Additionally, coach driver job-related stress is inherently complicated and involves multiple factors. A multi-variant methodology should be used in the research consideration, as well [2]. 
Previous publications have largely concerned general professional drivers and aberrant driving behavior [5]. Some have targeted coach drivers by examining job stressors [2,4,9] or linking them to tourism or transportation [2,4,10-12], but they have lacked an examination of cognitive coping. Recently, a multiple regression analysis by Liu and Huang [1] and a partial least squares (PLS) regression model by Liu et al. [3] both indicated that cognitive coping strategies were found mediating the job-related stress outcomes for coach drivers. Nevertheless, the results did not go further to address the more complicated relationships between variables beyond such a linear relationship. Nor were they able to provide strategies that are feasible to execute.

This research was motivated by the gaps in the literature cited above and used the empirical case of Taiwan to (1) examine the job-related stress of coach drivers from the transaction stress perspective, (2) understand the relationships between stressors, cognitive appraisal, and stress outcomes; (3) use a multivariate method to manage the complicated feedback in the relationships between these stress variables; and (4) propose a constructive improvement plan to help coach drivers and authorities better manage coach driver job-related stress for a sustainable coach tourism industry.

Corresponding to these purposes, the theoretical framework and methodological design of coach driver job stress were established. First, the evaluation system for coach driver job-related stress was established based on transaction stress theory. Then, the novel DEMATEL-based ANP and VIKOR (DANP-V) model was used to identify the influential relationships between criteria and the gaps between the actual and the desired levels. The DANP-V is a robot combination technique in multiple-criteria decision-making (MCDM). It is superior when analyzing complicated problems and relationships beyond the linear relationship [13].

The remainder of this paper is organized as follows. In the next section, the existing literature regarding coach drivers in Taiwan, stress theory, coach driver job-related stress, and the DANP-V model are reviewed. In Section 3, a novel DANP-V model evaluation system is created. In Section 4, an empirical case for a plan for relieving coach driver job-related stress is illustrated to show the usefulness of the proposed model. Finally, conclusions are presented in Section 5.

Table 1. Fatal coach traffic accidents caused by driver error between 2012 and 2017 in Taiwan.

\begin{tabular}{|c|c|c|c|}
\hline Day-Month-Year & Accident Description & Fatalities & Suspected Cause \\
\hline $17-2-2012$ & $\begin{array}{l}\text { Rushing on the east coast high way } \\
\text { to next stop }\end{array}$ & $\begin{array}{l}1 \text { dead } \\
32 \text { wounded }\end{array}$ & Speeding \\
\hline $24-8-2012$ & $\begin{array}{c}\text { Bumping into the automobile tunnel } \\
\text { in Tainan }\end{array}$ & 23 wounded & Driver fatigue \\
\hline $22-4-2013$ & $\begin{array}{l}\text { To pass a car, crossed into the } \\
\text { opposite side of road on Mt. Ali }\end{array}$ & 20 wounded & Rushing to the next stop \\
\hline $19-7-2016$ & $\begin{array}{l}\text { Coach on fire as driving on high way } \\
\text { to Taoyuan International Airport }\end{array}$ & 26 dead & $\begin{array}{l}\text { Distress. The driver set a fire to } \\
\text { kill himself and all the passengers }\end{array}$ \\
\hline $13-2-2017$ & $\begin{array}{l}\text { Failed to make a turn and fell down } \\
\text { a slope in Mucha }\end{array}$ & $\begin{array}{l}33 \text { dead } \\
11 \text { wounded }\end{array}$ & $\begin{array}{l}\text { Extreme fatigue due to driving for } \\
18 \text { days consecutively }\end{array}$ \\
\hline
\end{tabular}

\section{Literature Review}

\subsection{Coach Driver and Coach Tourism in Taiwan}

A coach refers to a bus used for transporting people or contracted to continually transport attendees between facilities during a certain time period [14]. These buses are used for sightseeing and a mix of private hire bookings, express connections, and tour management. With the superiority of high mobility and rapid changes in location, a coach package tour is an effective way for travelers to visit the largest number of sites on a trip of a given duration $[15,16]$. It allows tourists to see as much as possible within a short period of time $[17,18]$. In this context, coach tourism is a form of package tour whereby tour operators or wholesalers bundle transport, accommodation, and other components into a product that is sold to tourists, mostly through travel agents [10]. The coach tour can be of many varieties, such as short escape, day excursions, extended coach holidays, and long-distance coaching. 
Based upon the definitions above, a coach driver can be identified as the driver hired to transport and serve tourists and conduct the coach tour in the context of coach tourism. In Taiwanese coach tourism, a coach driver is different from a normal bus driver because the job requires the driver to engage in specific job functions, including (1) to drive and serve a group of tourists for a period of time, most often for long-distance coach holidays; (2) to do chores, and please and protect tourists; (3) to work with a Taiwanese tour guide or tour leader (e.g., requirement specific for the group package tour (GPT) of mainland China) throughout the journey; (4) to be away from home, office, and associates; (5) to be alert at all times, isolated behind the wheel, and charged with directing the journey most of the time; (6) to transport GPT after GPT during the high season and do nothing but wait for next one during the low season $[1,2,5,9,19]$.

In this scenario of coach tourism, it is "the sequencing of events that culminate in the experience of stress" [20]. In addition to insufficient family interaction (long work hours, no paid leave, and long periods of absence from the home), Taiwanese coach drivers also suffer poor relationship bonds in the workplace. Their relationship with the coach company is typically shallow and unbounded. They are hired on contract by coach companies to support tour operators. Approximately $40 \%$ of drivers are independent coach owners who are licensed to a coach company just because of policy requirements [1]. In this circumstance, they suffer from unstable work, unpredictable income, and inadequate employment protection. Conflicts with supervisors are common in the area of rights and regulations. On the journey, drivers function not only as drivers but also as cleaners, porters, escorts, and technicians. However, these drivers are not covered by GPT-related insurance because they are not members of the GPT. Some arguments may also arise because of the demanding tourists and tip/commission sharing between coworkers, guides, and escorts. In sum, the drivers have lower social-economic status both on the journey and in the workplace [2,4].

Under such an imbalance between the person and the environment [21], coach drivers in Taiwan are susceptible to job-related stress [1,2,4]. A useful improvement scheme addressing this particular type of coach driver in the work environment of coach tourism is an urgent challenge for decision-makers.

\subsection{Coach Driver Job Stressors and Stress Outcomes}

The father of the concept of stress, Hans Selye, reports that stress is the non-specific response of the body to any demand made upon it [22]. Greenberg [23] defined it more precisely as stress is the physical, mental or emotional reaction resulting from an individual's response to environmental tension, conflicts, pressure, and other stimuli. In this context, stress is ubiquitous in our lives, as any demand upon the body may cause stress [24]. Stress can be seen as having both positive and negative consequences for the individual. Too much stress causes physiological and psychological problems for individuals [25,26]. In common usage, stress is thus found at the negative end of the emotional spectrum.

Job stress is also known as work-related stress or occupational stress [24]. Cooper and Marshall [27] defined occupational stress as negative environmental factors or stressors (e.g., workload, role-related conflicts, role ambiguity, and poor working conditions) associated with a particular job. Smylie [28] defines the stressor as any physical, psychological, or cultural factor in an environment or any event which requires coping or adaptation. Greenberg [23] put it shortly: "An action or stimulus creating stress is a stressor." The stressors can be inside and outside of work, varying among people and occupations [29].

A great number of stressors have been identified in the human service work environment. Few are related to the coach drivers' stressors, but they are varied [1,2,4,9]. However, there are two things they have in common: the stressors of coach drivers are mainly related to family and the workplace. Liu and Huang [1] summarized these stressors in three aspects. (1) Interpersonal relationships: referring to the driver's poor family and workplace interactions, including insufficient family interaction, family worries, little support from the family, disallowed leave, and conflicts with supervisors/co-workers. (2) Intrinsic nature of the job: referring to the stressful nature inherent to the job, such as receiving little respect, complying with tourist requests, arguing with guides and escorts, and changing company 
management and government regulations. (3) Itinerary pressure: referring to pressure to complete an itinerary, specifically in cases of traffic congestion (in scenic areas in particular), rushing to complete a tight schedule, and long work hours and insufficient breaks.

The existing literature remarks that work-related stress can lead to varying levels of psychological tension and frustration and, ultimately, to job withdrawal, increases in intended turnover, and the decline of the physical, mental, and emotional well-being of the workforce $[25,26,30]$. These stress-related outcomes can be extrapolated to the Taiwanese coach drivers, as well. Liu and Huang [1] summarize these outcomes as (1) physical and psychological fatigue, referring to physical and psychological responses to negative job stress, such as feeling dispirited before work, exhausted after work, or a lack of appetite, polyphagia, or digestion disorder and (2) turnover intent, referring to the intention to change company or profession.

\subsection{Coach Drivers and Cognitive Coping Strategies}

Referring to stress, appraisal is the process by which we decide whether or not we feel stressed [31,32]. Lazarus proposed that the appraisal process is the cognitive mediator of stress, between person and environment, in which cognitive activities, such as evaluative perceptions, thoughts, and inference, are used by a person to interpret and guide every adaptational interchange with the environment [33]. This transactional view regards cognitive appraisal as leading the experiencing of stress. The individual perception is thus concerned with the aspect that cognitive appraisal might influence either the individual's perception of the situation or the way to cope with it [34]. Here, coping is considered in terms of a process. Coping encompasses the "constantly changing cognitive and behavioral efforts a person makes to manage specific external or internal demands that are appraised as taxing or exceeding the resources of the person" [35].

However, no consensus has been reached as to the coping categories [6]. Shinn et al. [36] proposed two categories of strategies (1) individual coping and (2) higher-level coping (social support and agency-supported strategies). Latack [37] developed three sorts of coping behavior: control, escape, and symptom-management. Lin et al. [38] found that Chinese coping methods to address job stress involved active action and passive avoidance. These typical Chinese coping strategies are used by Liu and Huang [1] in referring to coach driver job stress. They extracted coping strategies such as (1) mindset adjustment: referring to thinking about the stressful moment, including seeing things positively, doing one's best, accepting the facts, and trying to relax; (2) gossip and complaint: referring to gossiping or complaining with associates, possibly chatting with peers or complaining with other drivers; and (3) active action: referring to the use of implicit confidence strategies to cope with the stressful encounters [30], such as seeking medical assistance or counseling or engaging in recreational activities.

Based upon the above, coach driver stress can be viewed as the product of a complex transaction between individual needs, resources, and coach tourism environmental demands and constraints. The interaction between stressors, cognitive coping strategies, and stress outcomes is assumed to be a relational process [6]. Hence, this framework based on a transactional view within the context of coach tourism seems most applicable to the complex problem of coach driver stress.

\subsection{DANP-V Model and Coach Driver Job Stress}

The term DANP-V model was first used by Zhu et al. [13] to define the combination method of the DANP approach and VIKOR. The model originated in an MCDM system, using the concepts of DEMATEL, ANP [39], and the modified VIKOR. MCDM considers multiple criteria at the same time and helps the decision-maker estimate the best case by sorting cases according to the criteria of each of the available cases. It is regarded as a superior compromise solution tool for decision-makers to solve problems with conflicting, complicated, and unpredictable criteria [40,41]. Generally, MCDM can be incorporated with a number of methods, such as DEMATEL, DEMATEL-based ANP (DANP), and the modified VIKOR $[13,42,43]$. 
The DEMATEL technique extends beyond the traditional analytical model. It is assumed that the criteria are independent, and hierarchical in the structure, releasing feedback effects simultaneously. These effects can be calculated using matrices based on mathematical theories. The result can also be converted into a visual map, the influential network relation map (INRM). The INRM can intelligently depict network relationships between criteria to show complex relationships between them in a coordinate space. Using these inter-effects, the DEMATEL can combine with Saaty's ANP [39] to calculate the influential weights of each criterion. This combination is called DANP, deriving the influence weight of criteria based on the DEMATEL procedure [41]. Additionally, these influential weights enable the modified VIKOR method to calculate more efficiently the gap between the actual and the aspirational level [44-46]. DANP is an intelligent joint-method for the DANP-V model.

The original VIKOR is a compromise solution method for ranking [47]. Traditional VIKOR uses only the basic maximum-minimum concept, the positive-ideal point, and the negative-ideal point [48-50]. This method is often described as "picking the best apple among a barrel of rotten apples". Addressing this drawback, the modified VIKOR starts by setting the aspiration level and the worst level in the normalized performance matrix of each alternative for each criterion. By setting this benchmark for the best (aspirational level) choice, the mean group utility based on the sum of all individual regret (i.e., average overall performance gaps and those for each dimension and for each criterion) and the maximum regret (i.e., the maximum gap), an individual criterion can be more precisely calculated. Then, each dimension of the criteria can be obtained for priority improvement based on the weights derived by the DANP. This modified VIKOR is efficient in avoiding "choosing the best among inferior choices/options/alternatives" [13,41,42,46].

From the discussion above, it can be concluded that a novel DANP-V model combined with DEMATEL, DANP, and the modified VIKOR is a comprehensive technique and is especially useful in tackling the complicated problems related to improvement strategies. For this study, the approach allowed the achievement of the research purpose by (1) using DEMATEL to clarify the interrelated criteria of the relationships associated with coach driver job-related stress; (2) using DANP to calculate influence weights of these job stress criteria; (3) using the modified VIKOR to evaluate the performance of each criterion of job stress; and (4) being a comprehensive method which can address stress constants, such as stressors, coping strategies, and stress outcomes in this study as a whole. Thus, this research could produce concrete schemes to improve coach driver job stress (see Figures 1 and 2). 


\begin{tabular}{|c|c|c|}
\hline $\begin{array}{l}\text { What are the relationships between these } \\
\text { variables of coach driver stress? }\end{array}$ & $\begin{array}{l}\text { How to realize priority criteria } \\
\text { for managing coach driver stress? }\end{array}$ & $\begin{array}{l}\text { How to produce useful strategies to } \\
\text { manage coach driver stress? }\end{array}$ \\
\hline$\downarrow$ & $\downarrow$ & $\downarrow$ \\
\hline 1st Phase & 2nd Phase & 3th Phase \\
\hline $\begin{array}{l}\text { DEMATEL } \\
\text { Technique }\end{array}$ & $\begin{array}{c}\text { DANP } \\
\text { Technique }\end{array}$ & $\begin{array}{l}\text { Modified VIKOR } \\
\text { Technique }\end{array}$ \\
\hline ….......' & 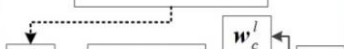 & \\
\hline $\begin{array}{c}\text { Innluential } \\
\text { Level }\end{array}$ & $\downarrow$ & $r_{k j}=\left(\left|f_{j}^{\text {aspired }}-f_{k j}\right|\right) /\left(\left|f_{j}^{\text {aspired }}-f_{j}^{\text {worst }}\right|\right)$ \\
\hline & $\nabla$ & 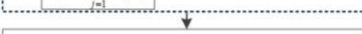 \\
\hline $\begin{array}{l}\quad \frac{\text { Obtain Influential Network }}{\text { Relation Map (INRM): }} \\
\text { INRM clarifying influence between mutual } \\
\text { criteria to offer the improvement direction }\end{array}$ & $\begin{array}{c}\text { Gain Influential Weights (IWs): } \\
\text { IWs for VIKOR to calculate gaps of } \\
\text { criteria }\end{array}$ & $\begin{array}{l}\text { Find Gaps of Criteria: } \\
\text { Gaps for sequencing the priorities and } \\
\text { making improvement strategies. }\end{array}$ \\
\hline \multicolumn{3}{|c|}{ 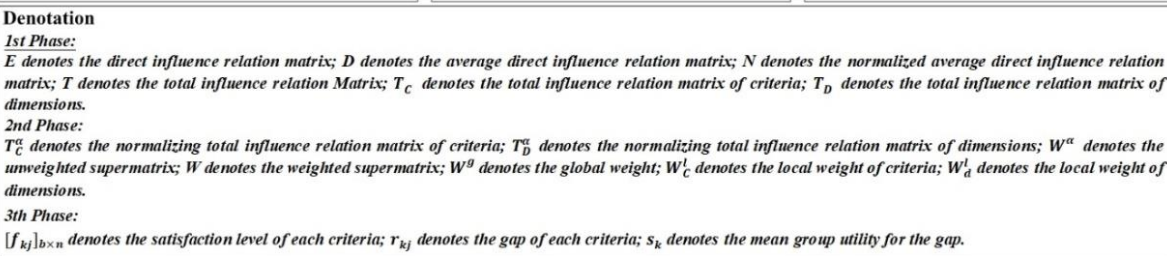 } \\
\hline
\end{tabular}

Figure 1. The research procedure of DEMATEL-based ANP and VIKOR (DANP-V) model of coach driver job stress.

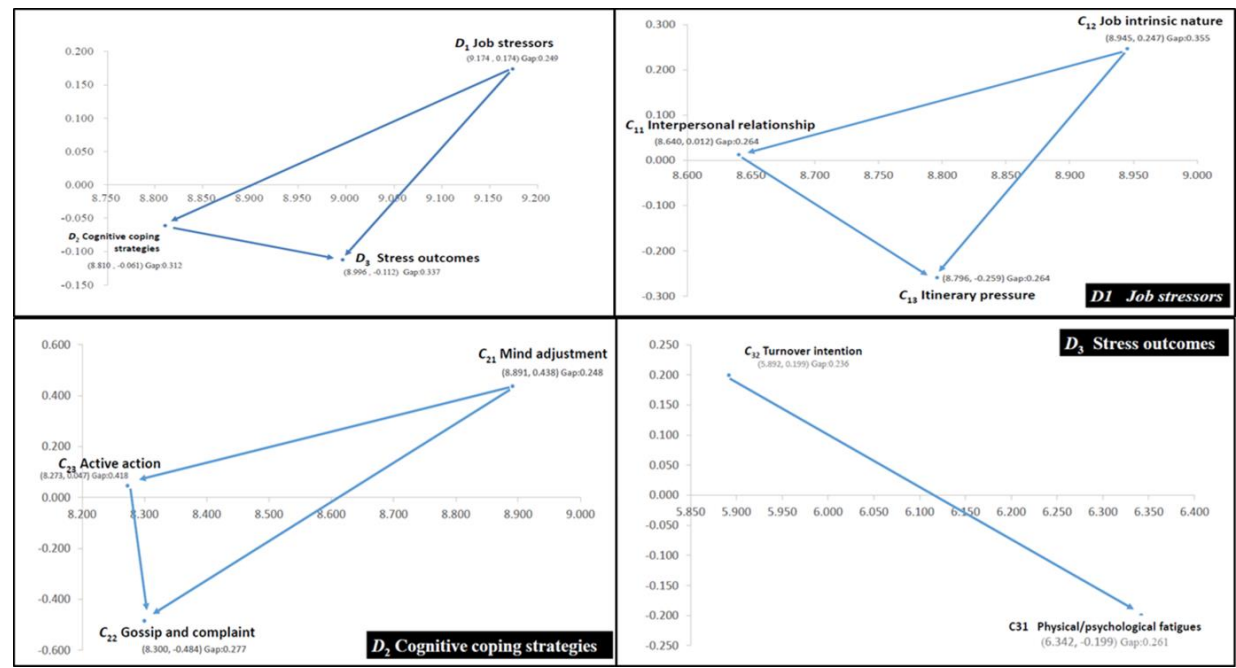

Figure 2. INRM (influential network relation map) of coach driver job stress.

\section{Methodology}

\subsection{Building an Evaluation System for a Coach Driver Job Stress}

The DNAP-V model originates from the MCDM technique. Building a multiple criteria evaluation system in a hierarchy layout is the first step [13]. Based on the literature review in Section 2, a coach driver evaluation system including three dimensions and eight criteria with 26 items within the context of coach tourism was established, see Table 2. Based on Liu and Huang [1], overall wording was edited for precise expression in accordance with the real world. For instance, in the criterion "interpersonal relationship", the item "no achievement as driver" has been changed to "feeling lonely and helpless" as it more accurately describes the consequence of poor interpersonal interactions. The expert group was composed of two drivers, two academics, and one authority. The $\alpha$ values were larger than 0.812 , showing a strong consensus between the experts. 
Table 2. Hierarchy evaluation system containing dimensions and criteria of coach driver job stress in coach tourism.

\begin{tabular}{|c|c|c|c|c|}
\hline GOAL & Dimensions/ $\alpha$ Values & Criteria & Contains/Items & Sources \\
\hline \multirow{8}{*}{$\begin{array}{l}\text { MANAGING COACH } \\
\text { DRIVER JOB STRESS }\end{array}$} & \multirow{3}{*}{$\begin{array}{l}\text { Job stressors }\left(D_{1}\right) \\
\qquad / 0.816\end{array}$} & Interpersonal relationship $\left(C_{1}\right)$ & $\begin{array}{l}\text { 1. Insufficient family interaction. } \\
\text { 2. Family worried about driving safety } \\
\text { 3. Little support from family } \\
\text { 4. Feeling lonely and helpless } \\
\text { 5. Conflict with supervisors/co-workers } \\
\text { 6. Leaves not allowed }\end{array}$ & \multirow{3}{*}[1-3,16,20,21,25,26]{} \\
\hline & & Job intrinsic nature $\left(C_{2}\right)$ & $\begin{array}{l}\text { 1. Low social-economic status } \\
\text { 2. Compliant to requests of tourists } \\
\text { 3. Arguments with escort/guide } \\
\text { 4. Inappropriate company management system } \\
\text { and government regulations }\end{array}$ & \\
\hline & & Itinerary pressure $\left(C_{3}\right)$ & $\begin{array}{l}\text { 1. Traffic congestion } \\
\text { 2. Rushing due to tight schedule } \\
\text { 3. Long working hours/insufficient breaks }\end{array}$ & \\
\hline & \multirow{3}{*}{$\begin{array}{l}\text { Cognitive coping strategies }\left(D_{2}\right) \\
\qquad / 0.683\end{array}$} & Mind-set adjustment $\left(C_{4}\right)$ & $\begin{array}{l}\text { 1. Seeing things positively } \\
\text { 2. Doing one's best } \\
\text { 3. Accepting the facts } \\
\text { 4. Trying to use certain tips to relax }\end{array}$ & \multirow{3}{*}[1,16,19,36,37]{} \\
\hline & & Gossip and complaint $\left(C_{5}\right)$ & $\begin{array}{l}\text { 1. Chatting with peers } \\
\text { 2. Complaining with other drivers }\end{array}$ & \\
\hline & & Active action $\left(C_{6}\right)$ & $\begin{array}{l}\text { 1. Seeking medical assistance/counseling } \\
\text { 2. Engaging in recreational activities }\end{array}$ & \\
\hline & \multirow{2}{*}{$\begin{array}{l}\text { Stress outcomes }\left(D_{3}\right) \\
/ 0.781\end{array}$} & $\begin{array}{l}\text { Physical/psychological fatigues } \\
\qquad\left(C_{7}\right)\end{array}$ & $\begin{array}{l}\text { 1. Dispirited before work } \\
\text { 2. Exhausted after work } \\
\text { 3. Lack of appetite, polyphagia, or bad digestion }\end{array}$ & \multirow{2}{*}[1,19,25-27]{} \\
\hline & & Turnover intention $\left(C_{8}\right)$ & $\begin{array}{l}\text { 1. Intent to change company } \\
\text { 2. Intent to change profession }\end{array}$ & \\
\hline
\end{tabular}

Note: Item underlined denotes wording has been edited and changed from the version of Liu and Huang (2018). 


\subsection{Sampling and Data Collection}

A pilot test of the measurement was conducted with a group of 30 experts (10 coach drivers, five authorities, five Independent Tour Operators, and 10 academics). The result showed that the values of Cronbach's $\alpha$ were all greater than 0.68 (respectively, in dimension order: $0.816,0.683$, 0.781), indicating the reliability of the instrument [51] (see Table 2). Subsequently, the questionnaire was distributed to The National Joint Association of Tourist Buses. This study used a representative sampling strategy to make inferences regarding a population [52]. In accordance with the coach driver definition (in Section 2.1), the sampled experts also met the additional requirements: (1) transporting GPTs for a period of time, (2) 10 years or more of experience in coach tourism, and (3) being a guild correspondent. They were randomly selected from the correspondent member list, and 24 were available during the interview period. Each interview (face-to-face) was approximately 30 minutes in duration. The consistency test showed significant confidence at $96.66 \%$ (larger than $95 \%$ ), indicating a strong consensus between the experts (the gap error was $0.34 \%$ ).

\subsection{Research Procedure}

In this study, the research procedure of the DANP-V model was divided into three phases (see Figure 1). In the first phase, the INRM of the dimensions and criteria was developed [13]. The purpose here was to clarify the mutual influence among the criteria of coach driver job stress. Through the questionnaire interview, the opinion of experts was collected (from 0 , no influence, to 4 , extreme influence) and integrated into the initial matrix using the method of the pairwise comparison (see Table A1). Subsequently, the DEMATEL technique was used to calculate the relation matrix of the total influence of dimensions $\left(T_{D}\right)$ and criteria $\left(T_{C}\right)$ (see Tables A2-A4). The INRM could thus be obtained (see Appendix A1).

In the second phase, the DANP technique (see Appendix A2) was used to develop the relation matrix of total influence from the first phase into influential weights (IWs) or global weights of the criteria (vector) using the basic concept of the operation process of ANP. The IWs were obtained by multiplying the Weighted Supermatrix $\mathrm{W}^{\alpha}$ itself till convergence (see Tables A5 and A6). The purpose was to distinguish the priority order based on the influence degree for VIKOR calculations.

In the third phase, the modified VIKOR method (see Appendix A3) was used to identify the gap between the actual and the aspiration level of each criterion. Criteria with smaller gaps were closer to the aspired level and larger gaps were farther from it [41]. According to these gap values, the improvement plan could be created and used to help manage coach driver job stress.

\section{Empirical Case Analysis for Coach Driver Job Stress}

This section assesses overall coach driver job stress to propose strategies for managing coach driver job stress using an empirical case of expert coach drivers in Taiwan. The data collected from these expert drivers were analyzed by the DANP-V model (see Appendix A). The results are presented in models that are useful for decision-making.

\subsection{Research Problems}

As mentioned above, coach tourism plays an important role in the Taiwanese tourism industry, including both inbound and domestic tours. With high mobility to destinations, coach tours are suitable for the island geography of Taiwan. Local tour operators thus bundle the GPTs and contract with coach companies [19]. However, fatal coach accidents have occurred in consecutive years, which has had a negative impact on the tourism industry and caused a huge social-economic cost on society (see Table 1). Many regulations, policies, and training programs were issued in an attempt to regulate driver behavior (such as laws promulgated by the Directorate General of Highway, MOC [53]). These changes have not stopped the fatal accidents from occurring in subsequent years, such as in 2016 and 2017. A number of studies point out that these accidents are mostly related to human error caused 
by job stress $[1,2,4,9]$. However, the question of "what to do and how" to help manage coach driver job stress effectively remains unanswered. A study that is able to tackle the relationships between job stress variables beyond the linear relationships to produce a physical action plan in response to the question is necessary.

\subsection{Results}

For the empirical case study, the dimensions and criteria of influence were calculated and illustrated using an INRM (see Appendix A1). The INRM (Figure 2) illustrates the structure of interactions regarding the stress process of coach drivers. Stress outcomes (D3) were influenced by job stressors (D1) and cognitive coping strategies (D2), whereas cognitive coping strategies (D2) were influenced by job stressors (D1). Obviously, the most influenced dimension was stress outcomes (D3); in contrast, the most influencing one is job stressors (D1). This network relationship pinpointed an improving sequence: D1-D2-D3. The efforts via network influence power would double up the effect on the influenced dimension(s). The same influence effects were found in the criteria as well. For instance, in job stressors (D1), according to influence values, the order could be sequenced as job intrinsic nature (C12), interpersonal relationships (C11), and itinerary pressure (C13). Similarly, in the cognitive coping strategies (D2), the influencing effect could be ordered as mindset adjustment (C21), active action (C23), and gossip and complain (C22). Then, in the stress outcomes (D3), the order could be sequenced as turnover intention (C32) and physical/psychological fatigue (C31). These orders imply the improvement priority.

Moreover, the gap values calculated by the modified VIKOR (see Appendix A3) showed the achievable degree to the aspired level (from low to high) (Table 3). On average, the performance scored 7.003 (to 10), and the gap to aspiration level was 0.300 (to 0 ). In the dimensions, this result showed that the stress outcomes (D3) had the smallest gap value, followed by cognitive coping strategies (D2) and job stressors (D1). To reach the aspired level, the achievement priority could be sequenced as D3-D2-D1. In the criteria, turnover intention (C32) had the smallest gap, followed by mind adjustment (C21) and physical/psychological fatigue (C31). Notably, the largest gap value was seen in active action (C23) with 0.418 , followed by itinerary pressure (C13) and job intrinsic nature (C12), indicating that these were the most unachievable criteria.

Table 3. The performance evaluation of the case study using the modified VIKOR.

\begin{tabular}{ccccc}
\hline Dimensions/Criteria & Global Weight & Local Weight & Performance & Gap \\
\hline $\boldsymbol{D}_{\mathbf{1}}$ Job stressors & $\mathbf{0 . 3 3 7}$ & & $\mathbf{6 . 6 2 9}$ & $\mathbf{0 . 3 3 7}$ \\
$C_{11}$ Interpersonal relationships & 0.328 & 0.111 & 7.364 & 0.264 \\
$\boldsymbol{C}_{12}$ Job intrinsic nature & 0.332 & 0.112 & 6.455 & 0.355 \\
$C_{13}$ Itinerary pressure & 0.340 & 0.115 & 6.091 & 0.391 \\
$\boldsymbol{D}_{\mathbf{2}}$ Cognitive coping strategies & $\mathbf{0 . 3 2 9}$ & & $\mathbf{6 . 8 7 6}$ & $\mathbf{0 . 3 1 2}$ \\
$\boldsymbol{C}_{21}$ Mind adjustment & 0.338 & 0.111 & 7.523 & 0.248 \\
$C_{22}$ Gossip and complaint & 0.342 & 0.113 & 7.227 & 0.277 \\
$C_{23}$ Active action & 0.320 & 0.105 & 5.818 & 0.418 \\
$\boldsymbol{D}_{3}$ Stress outcomes & $\mathbf{0 . 3 3 4}$ & & $\mathbf{7 . 5 0 7}$ & $\mathbf{0 . 2 4 9}$ \\
$C_{31}$ Physical/psychological fatigues & 0.535 & 0.178 & 7.394 & 0.261 \\
$\boldsymbol{C}_{32}$ Turnover intention & 0.465 & 0.155 & 7.636 & 0.236 \\
\hline Total Performance & & & 7.003 & \\
Total Gap & & & & $\mathbf{0 . 3 0 0}$ \\
\hline
\end{tabular}

\subsection{Discussions}

Based upon the analysis above, a complex relationship between the criteria of coach driver job stress was unraveled by the DANP-V model. The INRM (Figure 2) illustrates a network-subnetwork relationship between dimensions, inside dimensions, and between criteria, with direct-indirect influence. It allows us to figure out influential network relations beyond a linear relationship (e.g., the multiple regression analysis [1] or partial least squares (PLS) regression model [3]). 
Moreover, the modified VIKOR analyzed the gap distance of each criterion to the optimal level. It is a novel finding in similar researches (e.g., [1-4]). On average, job stressors (D1) had larger gaps, reflecting real and profound worries existing in coach driver's workplace. Worse still, the deduction of Chinese mainland tourist arrivals has brought a severe impact on coach tourism since 2016. The majority of the drivers (32.9\%) had the meager monthly income of 1000-1300 USD and worked 12 $\mathrm{h}$ or more per day [3], along with uncertain employment due to lacking tourists to transport [54].

Therefore, this empirical result supports the transaction stress theory [33,55] using an INRM. With the meaningful implications, it can thus serve to solve the problem of current job stress with tentative insights both in theoretical and practical fields.

\subsection{Implications}

From the DANP-V model result, the implications emerge and suggest useful managerial revelations for decision-makers. It could be further sum up as improvement schemes for executive actions.

\subsubsection{Theoretical Implications}

In the INRM (Figure 2), the mediator effects existing in the influential process could be seen: job stressors via cognitive coping strategies to stress outcomes. In the meantime, the map illustrates more direct influential relationships of dimensions: (1) from job stressors to cognitive coping strategies, (2) from job stressors to stress outcomes, and (3) from cognitive coping strategies to stress outcomes. Similar relationships are also depicted in the subnetwork relationship between the criteria depicted in each dimension. These relationships are holistic and individual and coexist in the coordinate space with network and subnetwork systems. These findings may be useful in deepening the transaction stress theory using network relation structure and in facilitating further research.

\subsubsection{Managerial Implications}

First, the improvement plan can start with influential network effects. According to the INRM (Figure 2), the most influential dimension/criterion is job stressors (D1) and job intrinsic nature (C12). It can be interpreted that coach drivers recognize that job stressors must come first, in particularly job-intrinsic-nature-related stressors. This finding is consistent with previous research that has suggested coach driver job intrinsic nature (e.g., low socio-economic status, changing company management system/government regulations) should be improved to address driver rights and protections [1-4]. Specifically, it is necessary to regulate the coach-owner drivers (approximately 40\%) who are just licensed to a coach company to fulfill requirements. For the well-being of individual drivers and the sector as a whole, the authorities should bear this in mind [56]. The INRM points out that the efforts in this direction will produce network effects on the remaining dimensions/criteria and will spontaneously resolve multiple issues. Hence, we suggest eliminating the job stressors as the first priority to prevent coach driver job stress.

Additionally, mind adjustment (C21) is confirmed to have a more influential effect on the other criteria in the cognitive coping strategies (D2). The finding is supported because passive avoidance would worsen the negative impact of stress. Positive thinking would bring out active action in the problem-focused approach [38,39]. In addition, more attention should be given to turnover intent (C32) which is more influential than physical/psychological fatigue (C31) in stress outcomes (D3). This finding suggests changing drivers' turnover intent first, then the relevant effects would extend to reduce their physical/psychological fatigue.

Moreover, the gap values of the modified VIKOR convey the significant methods to reach the aspired levels (Table 3). In dimensions, the most achievable one should be stress outcomes (D3), with the smallest gap between the actual and the aspired level. This is reconfirmed by its well-performing criteria, turnover intention (C32) (with the smallest gap) and physical/psychological fatigue (C31) (the second smallest gap). In the real world, most of the drivers are devoted and reluctant to withdraw from the tourist transportation profession [19]. This may be because coach driving is the only profession for 
them [19], or they made a mind adjustment (C21) (second smallest gap). A slightly improved work environment is enough to make them stay. They understand that the job stressor (D1) (dimension of the largest gap) is unlikely to reach their desired level in a short time. Hence, we suggest reducing the stress outcomes as the first priority to reach the aspired level of job stress.

Finally, the most unachievable criterion is active action (C23) with the largest gap value of 0.418 , implying it could not be neglected for a long term goal. The lack of using higher-level coping strategies, such as social support and agency-supported strategies [36] or symptom management [37] threatens the adaptations of current drivers. Similar to the issue of drivers' rights and obligations, these strategies have not been taught or discussed in the training/educational package [1,53]. The driver suspected of starting the coach fire killing all the passengers in 2017 (Table 1) may be the victim of such helplessness. However, no active action has been advised for coach drivers. Kompier [26] suggested that the elimination of stressors (the primary prevention) and increase coping capacity (the secondary prevention) are workplace-oriented. The tertiary prevention should be person-oriented, concerning treatment activities directed to individuals, such as counseling. Hence, we suggest teaching coach drivers active action to cope with job stress as a long term strategy.

Given these empirical findings, more suggestions can be summarized and demonstrated for what to do/how to help (see Table 4). These solutions are formulated for improving coach driver job stress to ultimately sustain the coach tourism industry. They can be unique and integral and simply indexed. For instance, to improve the job stressors (D1), the priority is C12-C11-C13. The action plan should start with the job intrinsic nature. The influential network effects are assumed to extend to interpersonal relationships and itinerary pressure spontaneously and make the improvement more effectively. More concrete schemes can be produced by employing this approach to yield twice the result with half the effort.

Table 4. Solutions to managing coach driver job stress.

\begin{tabular}{clc}
\hline \multicolumn{1}{c}{ Goal } & \multicolumn{1}{c}{ Formula } & Sequence of Action Priority \\
\hline \multirow{2}{*}{\begin{tabular}{c} 
Improving the negative job stress $\begin{array}{c}\text { F1: by influential weights of } \\
\text { using network effects } \\
\text { dimensions (from high to low) }\end{array}$ \\
\cline { 2 - 3 }
\end{tabular}} & $\begin{array}{l}\text { F2: by influential weights of } \\
\text { criteria (from high to low) }\end{array}$ & D1-D2-D3 \\
\cline { 2 - 3 } $\begin{array}{c}\text { Reaching the aspired level by } \\
\text { bridging the gaps }\end{array}$ & $\begin{array}{l}\text { F3: by gap value of dimensions } \\
\text { (from low to high) }\end{array}$ & $\begin{array}{l}\text { C12-C11-C13 } \\
\text { C21-C23-C22 }\end{array}$ \\
\cline { 2 - 3 } & F4: by gap value of criteria (from & C32-C31 \\
\hline
\end{tabular}

\section{Conclusions}

The empirical test of our approach was conducted using a case study of Taiwanese expert drivers within the context of coach tourism. The result illustrated the usefulness of the DANP-V approach in dealing with complex job stress and suggested meaningful implications (Table 4). Thus, our study may be superior in (1) developing the INRM, which is able to depict holistic and individual interactions beyond a linear relationship, (2) using the gap values to more precisely select the best option among the bests, and (3) using the Excel program, which is more straightforward and simpler than a traditional computation package (see Appendices A and B).

This research was intended to contribute to (1) establishing a theoretical framework addressing coach driver job stress, (2) demonstrating the novel tool of DANP-V models for examining complicated feedback and relationships between coach driver job-related stress variables, (3) proposing useful stress-relief strategies specifically for coach drivers, and (4) ultimately, helping to manage coach driver job-related stress and sustain the coach tourism industry. 
However, there are some limitations to the research. First, the measurement scale developed in this study may not have the generalizability for cross-industry/country application because it is industry-specific and captures a narrow domain by definition in the case of Taiwan. Second, the content and focus of the present study have been essentially driver-oriented. A comparison between management staff and officials would have deepened the discussion. Finally, further research is needed in the field to develop a more elaborate multi-criteria structure that incorporates both large management samples and official samples.

Funding: This research was funded by Ministry of Science and Technology, Taiwan, grant number: 106-2410-H-454-018.

Conflicts of Interest: The authors declare no conflict of interest.

\section{Appendix A. Research Steps}

The DANP-V model was proposed by Tzeng et al. [13,41], including three techniques: the DEMATEL, the DANP, and the modified VIKOR. Thus, the process is divided into three steps as follows [13].

\section{Appendix A.1. DEMATEL Technique}

Step 1: Establish the direct influence relation matrix $E$. Data is obtained using the questionnaire with a scale ranging from 0 , no influence, to 4 , extreme influence. The pairwise comparison method is used to evaluate the degree of influence of the criteria, showing the degree each criterion $i$ affects each criterion $j$. This matrix must be a $n \times n$ nonnegative matrix. According to the results from $H$ experts, the direct influence relation matrix $E$ is shown in Equation (A1), and the direct influence relation matrix from all experts is $E^{h}=\left[e_{i j}^{h}\right]_{n \times n^{\prime}}, h=1,2, \ldots, H$, where $E^{1}, \ldots, E^{h}, \ldots, E^{H}$.

$$
E=\left[\begin{array}{ccccc}
e_{11} & \cdots & e_{1 j} & \cdots & e_{1 n} \\
\vdots & & \vdots & & \vdots \\
e_{i 1} & \cdots & e_{i j} & \cdots & e_{i n} \\
\vdots & & \vdots & & \vdots \\
e_{n 1} & \cdots & e_{n j} & \cdots & e_{n n}
\end{array}\right]
$$

Step 2: Constitute the average direct influence relation matrix $\boldsymbol{D}$. The average scores of the $H$ experts are $d_{i j}=\frac{1}{H} \sum_{h=1}^{H} e_{i j}^{h}$. The average matrix is called the average direct influence relation matrix $\boldsymbol{D}$. The matrix $D$ represents the degree of influence that one criterion exerts on another and the degree of influence that the criterion receives from another, as shown in Equation (A2):

$$
D=\left[\begin{array}{ccccc}
d_{11} & \cdots & d_{1 j} & \cdots & d_{1 n} \\
\vdots & & \vdots & & \vdots \\
d_{i 1} & \cdots & d_{i j} & \cdots & d_{i n} \\
\vdots & & \vdots & & \vdots \\
d_{n 1} & \cdots & d_{n j} & \cdots & d_{n n}
\end{array}\right] .
$$

Step 3: Examine consensus. The value of consensus can be estimated by Equation (A3), which represents the level of experts' consensus. The threshold of the average gap ratio is $5 \%$, implying a confidence level above $95 \%$. Conversely, if an unstable system is obtained, the first phase should be implemented again to verify whether data collection is correct or the number of experts is sufficient.

$$
\text { Average gap - ratio inconsensus }(\%)=\frac{1}{n(n-1)} \sum_{i=1}^{n} \sum_{j=1}^{n}\left(\left|d_{i j}^{H}-d_{i j}^{H-1}\right| / d_{i j}^{H}\right) \times 100 \%
$$


Step 4: Formulate the normalized average direct influence relation matrix $N$. The normalized average direct influence relation matrix $N$ is acquired by normalizing the matrix $D$. The matrix $N$ is easily derived from Equations (A4) and (A5), in which all principal diagonal criteria are equal to 0.

$$
b=\min \left\{\frac{N=b \cdot \boldsymbol{D}}{\max _{1 \leq i \leq n} \sum_{j=1}^{n} d_{i j}}, \frac{1}{\max _{1 \leq j \leq n} \sum_{i=1}^{n} d_{i j}}\right\} .
$$

Step 5: Construct the total influence relation matrix $T$. A continuous decrease of the indirect effects of problems moves with the powers of the matrix $N$, e.g., $N^{2}, \ldots, N^{\infty}$, and $\lim _{q \rightarrow \infty} N^{q}=[0]_{n \times n}$, for $\lim _{q \rightarrow \infty}\left(\boldsymbol{I}+\boldsymbol{N}+\boldsymbol{N}^{2}+\ldots+\boldsymbol{N}^{q}\right)=(\boldsymbol{I}-\boldsymbol{N})^{-1}$, where $\boldsymbol{I}$ is a $n \times n$ unit matrix. The total influence relation matrix $\boldsymbol{T}$ is a $n \times n$ matrix and is defined by $\boldsymbol{T}=\left[t_{i j}\right]_{n \times n^{\prime}} i, j=1,2, \ldots, n$, as shown in Equation (A6).

$$
\begin{gathered}
T=N+N^{2}+\ldots+N^{q}=N\left(I+N+N^{2}+\ldots+N^{q-1}\right) \\
=N\left(I+N+N^{2}+\ldots+N^{q-1}\right)(I-N)(I-N)^{-1} \\
=N(I-N)^{-1}, \text { when } \lim _{q \rightarrow \infty} N^{q}=[0]_{n \times n}
\end{gathered}
$$

Step 6: Obtain INRM. The total influence relation matrix $T$ of INRM can be acquired using Equations (A7) and (A8) to generate each row sum and column sum in the matrix $T$.

$$
\begin{gathered}
\boldsymbol{o}=\left(o_{i}\right)_{n \times 1}=\left[\sum_{j=1}^{n} t_{i j}\right]_{n \times 1}=\left(o_{1}, \ldots, o_{i}, \ldots, o_{n}\right) \\
\boldsymbol{r}=\left(r_{i}\right)_{n \times 1}=\left(r_{j}\right)^{\prime}{ }_{1 \times n}=\left[\sum_{i=1}^{n} t_{i j}\right]^{\prime} 1 \times n=\left(r_{1}, \ldots, r_{j}, \ldots, r_{n}\right)^{\prime},
\end{gathered}
$$

where $o_{i}$ is the sum of a row in the total influence relation matrix $T$, which represents the total effects (both direct and indirect) of criterion/perspective $i$ on all other criteria/perspectives $\left[\sum_{j=1}^{n} t_{i j}\right]_{n \times 1}$. Similarly, $r_{j}$ is the column sum in the total influence relation matrix $T$, which represents the total effects (both direct and indirect) of criterion/perspective $j$ received from all other criteria/perspectives $\left[\sum_{i=1}^{n} t_{i j}\right]_{1 \times n}^{\prime} .\left(o_{i}+r_{i}\right)$ provides an index of the strength of the total influences given and received. That is, $\left(o_{i}+r_{i}\right)$ indicates the degree of importance of the criterion/perspective $i$ in the system. In addition, $\left(o_{i}-r_{i}\right)$ provides an index of the degree of the cause of the total influence. If $\left(o_{i}-r_{i}\right)$ is positive, then criterion/perspective $i$ is a net causer, and if $\left(o_{i}-r_{i}\right)$ is negative, then criterion/perspective $i$ is a net receiver.

Step 7: Construct the total influence relation matrix of criteria $\boldsymbol{T}_{C}$ and dimensions $\boldsymbol{T}_{D}$. The total influence relation matrix of criteria $\boldsymbol{T}_{C}$ from each dimension, with different degrees of influence relation for the criteria, is shown in Equation (A9), where $\sum_{j=1}^{m} m_{j}=n, m<n$, and $\boldsymbol{T}_{c}^{i j}$ as a $m_{i} \times m_{j}$ matrix.

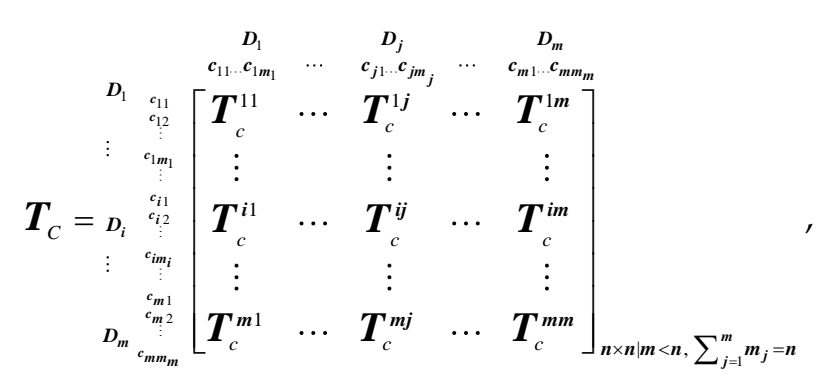


where $D_{m}$ is the $m$ th cluster; $c_{m m}$ is the $m$ th criterion in the $m$ th dimension; and $\boldsymbol{T}_{C}^{i j}$ is a submatrix of the influence relation for the criteria from a comparison of the $i$ th dimension with the $j$ th dimension. In addition, if the $i$ th dimension has no influence on the $j$ th dimension, submatrix $T_{C}^{i j}=[0]$, demonstrates the independence (no influence relation) of each criterion on other criteria. Moreover, the total influence relation matrix of dimension $T_{D}$ is shown in Equation (A10):

$$
\boldsymbol{T}_{D}=\left[\begin{array}{ccccc}
t_{11} & \cdots & t_{1 j} & \cdots & t_{1 m} \\
\vdots & & \vdots & & \vdots \\
t_{i 1} & \cdots & t_{i j} & \cdots & t_{i m} \\
\vdots & & \vdots & & \vdots \\
t_{m 1} & \cdots & t_{m j} & \cdots & t_{m m}
\end{array}\right]_{m \times m}
$$

Appendix A.2. DANP Technique

Step 1: Calculate the unweighted supermatrix $W^{\alpha}$. Normalize the total influence relation matrix $T_{C}$ by dimensions as shown in Equation (A11):

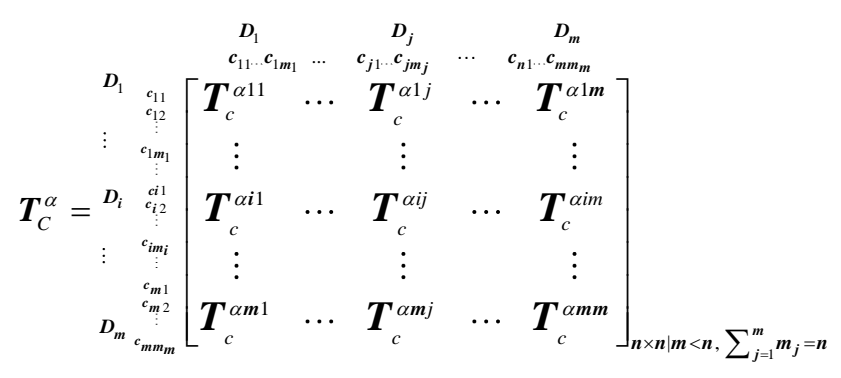

where $T_{C}^{\alpha}$ denotes the normalizing total influence relation matrix of criteria by dimensions. $T_{c}^{\alpha 14}$ is derived from Equations (A12) and (A13). Similarly, $\boldsymbol{T}_{c}^{\alpha m m}$ can be obtained:

$$
\begin{aligned}
& t_{i}^{14}=\sum_{j=1}^{m_{4}} t_{i j}^{14}, i=1,2, \cdots, m_{1} \\
& T_{c}^{\alpha 14}=c_{11} \begin{array}{c}
c_{11} \\
\vdots \\
\vdots \\
c_{1 m_{1}}
\end{array}\left[\begin{array}{ccccc}
t_{11}^{14} / t_{1}^{14} & \cdots & t_{1 j}^{14} / t_{1}^{14} & \cdots & t_{1 m_{4}}^{14} / t_{1}^{14} \\
\vdots & & \vdots & & \vdots \\
t_{i 1}^{14} / t_{i}^{14} & \cdots & t_{i j}^{14} / t_{i}^{14} & \cdots & t_{i m_{4}}^{14} / t_{i}^{14} \\
\vdots & & \vdots & & \vdots \\
t_{m_{1} 1}^{14} / t_{m_{1}}^{14} & \cdots & t_{m_{1} j}^{14} / t_{m_{1}}^{14} & \cdots & t_{m_{1} m_{4}}^{14} / t_{m_{1}}^{14}
\end{array}\right]=\left[\begin{array}{ccccc}
t_{11}^{\alpha 14} & \cdots & t_{1 j}^{\alpha 14} & \cdots & t_{1 m_{4}}^{\alpha 14} \\
\vdots & & \vdots & & \vdots \\
t_{i 1}^{\alpha 14} & \cdots & t_{i j}^{\alpha 14} & \cdots & t_{i m_{4}}^{\alpha 14} \\
\vdots & & \vdots & & \vdots \\
t_{m_{1} 1}^{\alpha 14} & \cdots & t_{m_{1} j}^{\alpha 14} & \cdots & t_{m_{1} m_{4}}^{\alpha 14}
\end{array}\right]
\end{aligned}
$$


According to the pairwise comparisons of the criteria and the basic concept of ANP, the unweighted supermatrix $W^{\alpha}$ can be obtained by transposing the normalized influence relation matrix $T_{C}^{\alpha}$ by dimensions. That is $\boldsymbol{W}^{\alpha}=\left(\boldsymbol{T}_{C}^{\alpha}\right)^{\prime}$ in Equation (A14):

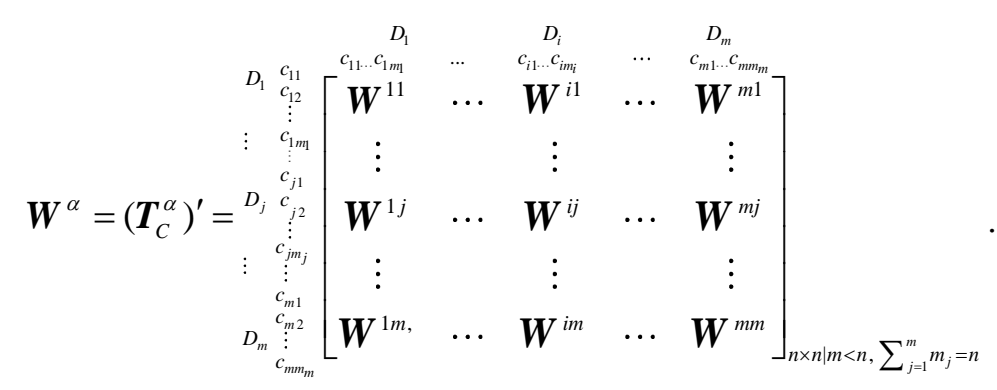

Step 2: Calculate weighted supermatrix. The normalized total influence-relation matrix of dimensions $\boldsymbol{T}_{D}^{\alpha}$ can be obtained through the total influence-relation matrix $\boldsymbol{T}_{D}$ divided by $d_{i}=\sum_{j=1}^{m} t_{i j}$, $i=1,2, \ldots, m$, as shown in Equation (A15).

$$
\mathbf{T}_{D}^{\alpha}=\left[\begin{array}{ccccc}
t_{11} / \mathrm{d}_{1} & \cdots & t_{1 j} / d_{1} & \cdots & t_{1 m} / d_{1} \\
\vdots & & \vdots & & \vdots \\
t_{i 1} / d_{i} & \cdots & t_{i j} / d_{i} & \cdots & t_{i m} / d_{i} \\
\vdots & & \vdots & & \vdots \\
t_{m 1} / d_{m} & \cdots & t_{m j} / d_{m} & \cdots & t_{m m} / d_{m}
\end{array}\right]_{m \times m}=\left[\begin{array}{ccccc}
t_{11}^{\alpha D} & \cdots & t_{1 j}^{\alpha D} & \cdots & t_{1 m}^{\alpha D} \\
\vdots & & \vdots & & \vdots \\
t_{i 1}^{\alpha D} & \cdots & t_{i j}^{\alpha D} & \cdots & t_{i m}^{\alpha D} \\
\vdots & & \vdots & & \vdots \\
t_{m 1}^{\alpha D} & \cdots & t_{m j}^{\alpha D} & \cdots & t_{m m}^{\alpha D}
\end{array}\right]_{m \times m}
$$

The matrix $T_{D}^{\alpha}$ and the unweighted supermatrix $W^{\alpha}$ and the weighted supermatrix $W$ can be easily obtained by Equation (A16), where $t_{i j}^{\alpha D}$ is a scalar. $\sum_{j=1}^{m} m_{j}=n$

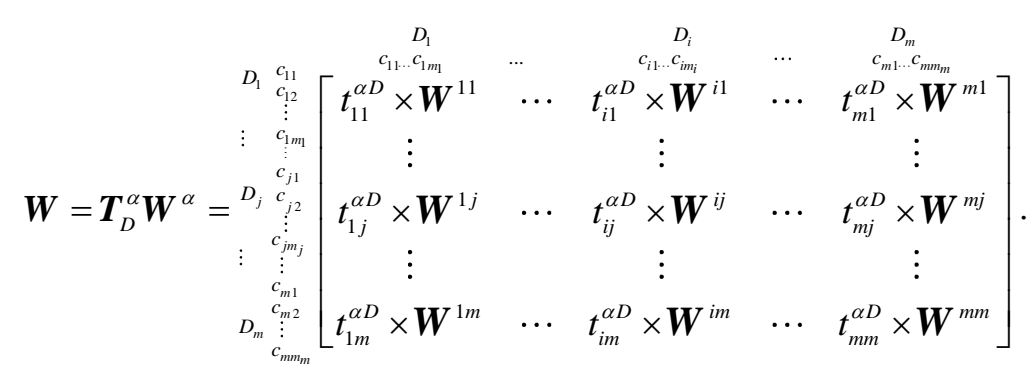

Step 3: Limit weighted supermatrix. Limit the weighted supermatrix by raising it to the $z$ th power until the supermatrix has converged and become a stable supermatrix. The global priority vectors, global weight $w^{g}$, the IWs of DANP, are obtained. It is $\lim _{z \rightarrow \infty}(\boldsymbol{W})^{z}$, where $z$ represents any number of power. By summing the IWs of each criterion in every dimension, the local weight of dimension $w_{D}^{l}$ can be obtained. Subsequently, the global weight of each criterion can be divided by the local weight of its own dimension to yield the local weight of criteria $w_{c}^{l}$.

\section{Appendix A.3. Modified VIKOR Method}

Step 1: Derive the positive ideal solution and the negative ideal solution replaced by the aspiration levels and the worst value to fit the current real-world situation. Define the best value (aspiration level) shown as $f_{j}^{\text {aspired }}$ in $\mathrm{j}$ criterion and the worst value $f_{j}^{\text {worst }}$ for all criteria, which can be acquired from the traditional form to the modified form.

(1) The traditional approach for deriving the positive ideal solution and negative ideal solution is as follows: The positive ideal solution: $f^{*}=\left(f_{1}^{*}, \ldots, f_{j}^{*}, \ldots, f_{n}^{*}\right)$, where $f_{j}^{*}=$ 
$\max _{k}\left\{f_{k j} \mid k=1,2, \ldots, b\right\}$; The negative ideal solution: $f^{-}=\left(f_{1}^{-}, \ldots, f_{j}^{-}, \ldots, f_{n}^{-}\right)$, where $f_{j}^{-}=$ $\min _{k}\left\{f_{k j} \mid k=1,2, \ldots, b\right\}$. This approach can only be used for the ranking and selection of alternatives and must be used for more than two alternatives, $f_{j}^{*}=\max _{k} f_{k j}$ and $f_{j}^{-}=\min _{k} f_{k j}$ when $k=1,2, \ldots, b$.

(2) The modified approach for replacement by the aspiration level and the worst value is, as follows: The aspiration level: $f^{\text {aspired }}=\left(f_{1}^{\text {aspired }}, \ldots, f_{j}^{\text {aspired }}, \ldots, f_{n}^{\text {aspired }}\right)$, where $f_{j}^{\text {aspired }}$ is an aspiration level, or called the best value; The worst values: $f^{\text {worst }}=\left(f_{1}^{\text {woorst }}, \ldots, f_{j}^{\text {worst }}, \ldots, f_{n}^{\text {worst }}\right)$, where $f_{j}^{\text {woorst }}$ is a worst value.

In this study, performance scores ranging from 0 to 10 (very bad $\leftarrow 0,1,2, \ldots, 9,10 \rightarrow$ very good) are used with natural language in the linguistic/semantic questionnaire. Hence, $f_{j}^{a s p i r e d}=10$ is defined as the aspiration level, and $f_{j}^{\text {worst }}=0$ as the worst value to avoid choosing the best among inferiors. It can thus avoid "picking the best apple from a barrel of rotten apples."

Step 2: Determine the mean group utility for the gap and then establish the priority improvement strategy. These values can be calculated using Equation (A17):

$$
s_{k}=\sum_{j=1}^{n} w_{j} r_{k j}=\sum_{j=1}^{n} w_{j}\left(\left|f_{j}^{\text {aspired }}-f_{k j}\right|\right) /\left(\left|f_{j}^{\text {aspired }}-f_{j}^{\text {worst }}\right|\right),
$$

where $s_{k}$ is defined as the normalized ratio (\%) of distance to the aspiration level, implying the synthesized gap of the criteria. $w_{j}$ indicates the IWs for the criteria obtained from DANP.

\section{Appendix B. Results of This Study in Detail}

The opinions of experts are measured using the total influence matrix $T$ and the degrees of influence. Table A1 shows the initial influence matrix $\boldsymbol{D}=\left[d_{i j}\right]_{n \times n}$ derived from the average value of the questionnaires. The consistency gap is $0.34 \%$ (smaller than $5 \%$ ), implying that the confidence level was $96.66 \%$.

Table A1 shows the relationship between the total influence matrix $\boldsymbol{T}$ and the degrees of influence. Table A2 illustrates the total relationships among the 8 criteria. Table A3 illustrates the total influence matrix of criteria Tc. Table A4 presents the sum of influences given or received from the degree of influence of each criterion within its own dimension.

The IWs of criteria were obtained from the ANP process in the DANP model. First, based on Equations (A9)-(A12), the unweighted supermatrix $\boldsymbol{W}^{\alpha}$ was obtained by transposing the normalized influence matrix $\boldsymbol{T}_{C}$, as shown in Table A3. The weighted supermatrix $\boldsymbol{W}$ based on Equations (A13) and (A14) is shown in Table A6. Then, the IWs of DANP were obtained by limiting the power of the weighted supermatrix, as shown in Table A6.

Table A1. Initial influence matrix $T$.

\begin{tabular}{ccccccccc}
\hline $\boldsymbol{D}$ & $\boldsymbol{C}_{\mathbf{1 1}}$ & $\boldsymbol{C}_{\mathbf{1 2}}$ & $\boldsymbol{C}_{\mathbf{1 3}}$ & $\boldsymbol{C}_{\mathbf{2 1}}$ & $\boldsymbol{C}_{\mathbf{2 2}}$ & $\boldsymbol{C}_{\mathbf{2 3}}$ & $\boldsymbol{C}_{\mathbf{3 1}}$ & $\boldsymbol{C}_{\mathbf{3 2}}$ \\
\hline$C_{11}$ & 0.00 & 2.27 & 2.18 & 2.64 & 2.36 & 2.73 & 2.27 & 2.27 \\
$C_{12}$ & 2.36 & 0.00 & 3.36 & 2.64 & 2.27 & 2.27 & 2.55 & 2.27 \\
$C_{13}$ & 1.73 & 1.82 & 0.00 & 2.73 & 2.00 & 2.64 & 2.91 & 2.73 \\
$C_{21}$ & 2.36 & 2.18 & 1.82 & 0.00 & 3.00 & 3.55 & 2.82 & 2.73 \\
$C_{22}$ & 2.55 & 2.45 & 2.00 & 1.55 & 0.00 & 1.91 & 2.91 & 2.09 \\
$C_{23}$ & 3.36 & 2.45 & 2.91 & 1.91 & 2.73 & 0.00 & 2.09 & 1.09 \\
$C_{31}$ & 2.45 & 3.27 & 3.09 & 2.91 & 2.18 & 1.64 & 0.00 & 2.64 \\
$C_{32}$ & 2.36 & 2.82 & 2.45 & 2.73 & 3.00 & 1.45 & 3.09 & 0.00 \\
\hline
\end{tabular}


Table A2. Normalized average direct influence relation matrix $N$.

\begin{tabular}{ccccccccc}
\hline$N$ & $C_{\mathbf{1 1}}$ & $C_{\mathbf{1 2}}$ & $C_{\mathbf{1 3}}$ & $C_{\mathbf{2 1}}$ & $C_{\mathbf{2 2}}$ & $C_{\mathbf{2 3}}$ & $C_{\mathbf{3 1}}$ & $C_{\mathbf{3 2}}$ \\
\hline$C_{11}$ & 0.00 & 0.12 & 0.12 & 0.14 & 0.13 & 0.15 & 0.12 & 0.12 \\
\hline$C_{12}$ & 0.13 & 0.00 & 0.18 & 0.14 & 0.12 & 0.12 & 0.14 & 0.12 \\
\hline$C_{13}$ & 0.09 & 0.10 & 0.00 & 0.15 & 0.11 & 0.14 & 0.16 & 0.15 \\
\hline$C_{21}$ & 0.13 & 0.12 & 0.10 & 0.00 & 0.16 & 0.19 & 0.15 & 0.15 \\
\hline$C_{22}$ & 0.14 & 0.13 & 0.11 & 0.08 & 0.00 & 0.10 & 0.16 & 0.11 \\
\hline$C_{23}$ & 0.18 & 0.13 & 0.16 & 0.10 & 0.15 & 0.00 & 0.11 & 0.06 \\
\hline$C_{31}$ & 0.13 & 0.18 & 0.17 & 0.16 & 0.12 & 0.09 & 0.00 & 0.14 \\
\hline$C_{32}$ & 0.13 & 0.15 & 0.13 & 0.15 & 0.16 & 0.08 & 0.17 & 0.00 \\
\hline
\end{tabular}

Table A3. Total influence matrix of criteria $T c$.

\begin{tabular}{ccccccccc}
\hline $\boldsymbol{T}_{\boldsymbol{c}}$ & $\boldsymbol{C}_{\mathbf{1 1}}$ & $\boldsymbol{C}_{\mathbf{1 2}}$ & $\boldsymbol{C}_{\mathbf{1 3}}$ & $\boldsymbol{C}_{\mathbf{2 1}}$ & $\boldsymbol{C}_{\mathbf{2 2}}$ & $\boldsymbol{C}_{\mathbf{2 3}}$ & $\boldsymbol{C}_{\mathbf{3 1}}$ & $\boldsymbol{C}_{\mathbf{3 2}}$ \\
\hline$C_{11}$ & 1.35 & 1.47 & 1.50 & 1.47 & 1.49 & 1.41 & 1.56 & 1.37 \\
$C_{12}$ & 1.53 & 1.43 & 1.63 & 1.55 & 1.56 & 1.46 & 1.65 & 1.44 \\
$C_{13}$ & 1.43 & 1.45 & 1.39 & 1.47 & 1.47 & 1.40 & 1.58 & 1.39 \\
$C_{21}$ & 1.59 & 1.59 & 1.61 & 1.47 & 1.64 & 1.56 & 1.72 & 1.50 \\
$C_{22}$ & 1.38 & 1.39 & 1.40 & 1.34 & 1.28 & 1.29 & 1.49 & 1.28 \\
$C_{23}$ & 1.48 & 1.45 & 1.51 & 1.42 & 1.48 & 1.26 & 1.53 & 1.30 \\
$C_{31}$ & 1.57 & 1.62 & 1.66 & 1.60 & 1.59 & 1.47 & 1.58 & 1.50 \\
$C_{32}$ & 1.55 & 1.58 & 1.61 & 1.57 & 1.60 & 1.44 & 1.69 & 1.35 \\
\hline
\end{tabular}

Table A4. Total influence matrix of dimensions $\boldsymbol{T}_{\boldsymbol{D}}$.

\begin{tabular}{cccc}
\hline $\boldsymbol{T}_{\boldsymbol{D}}$ & $\boldsymbol{D}_{\mathbf{1}}$ & $\boldsymbol{D}_{\mathbf{2}}$ & $\boldsymbol{D}_{\mathbf{3}}$ \\
\hline$D_{1}$ & 1.47 & 1.48 & 1.50 \\
$D_{2}$ & 1.49 & 1.41 & 1.47 \\
$D_{3}$ & 1.60 & 1.55 & 1.53 \\
\hline
\end{tabular}

Table A5. Weighted supermatrix.

\begin{tabular}{lcccccccc}
\hline$W^{\alpha}$ & $C_{\mathbf{1 1}}$ & $\boldsymbol{C}_{\mathbf{1 2}}$ & $\boldsymbol{C}_{\mathbf{1 3}}$ & $\boldsymbol{C}_{\mathbf{2 1}}$ & $\boldsymbol{C}_{\mathbf{2 2}}$ & $\boldsymbol{C}_{\mathbf{2 3}}$ & $\boldsymbol{C}_{\mathbf{3 1}}$ & $\boldsymbol{C}_{\mathbf{3 2}}$ \\
\hline$C_{11}$ & 0.31 & 0.33 & 0.33 & 0.33 & 0.33 & 0.33 & 0.32 & 0.33 \\
$C_{12}$ & 0.34 & 0.31 & 0.34 & 0.33 & 0.33 & 0.33 & 0.33 & 0.33 \\
$C_{13}$ & 0.35 & 0.35 & 0.33 & 0.34 & 0.34 & 0.34 & 0.34 & 0.34 \\
$C_{21}$ & 0.34 & 0.34 & 0.34 & 0.31 & 0.34 & 0.34 & 0.34 & 0.34 \\
$C_{22}$ & 0.34 & 0.34 & 0.34 & 0.35 & 0.33 & 0.35 & 0.34 & 0.35 \\
$C_{23}$ & 0.32 & 0.32 & 0.32 & 0.33 & 0.33 & 0.30 & 0.32 & 0.31 \\
$C_{31}$ & 0.53 & 0.53 & 0.53 & 0.53 & 0.54 & 0.54 & 0.51 & 0.56 \\
$C_{32}$ & 0.47 & 0.47 & 0.47 & 0.47 & 0.46 & 0.46 & 0.49 & 0.44 \\
\hline
\end{tabular}

Table A6. Weighted supermatrix $W$.

\begin{tabular}{ccccccccc}
\hline $\boldsymbol{W}$ & $\boldsymbol{C}_{\mathbf{1 1}}$ & $\boldsymbol{C}_{\mathbf{1 2}}$ & $\boldsymbol{C}_{\mathbf{1 3}}$ & $\boldsymbol{C}_{\mathbf{2 1}}$ & $\boldsymbol{C}_{\mathbf{2 2}}$ & $\boldsymbol{C}_{\mathbf{2 3}}$ & $\boldsymbol{C}_{\mathbf{3 1}}$ & $\boldsymbol{C}_{\mathbf{3 2}}$ \\
\hline$C_{11}$ & 0.10 & 0.11 & 0.11 & 0.11 & 0.11 & 0.11 & 0.11 & 0.11 \\
$C_{12}$ & 0.11 & 0.10 & 0.11 & 0.11 & 0.11 & 0.11 & 0.11 & 0.11 \\
$C_{13}$ & 0.11 & 0.12 & 0.11 & 0.11 & 0.11 & 0.12 & 0.12 & 0.12 \\
$C_{21}$ & 0.11 & 0.11 & 0.11 & 0.10 & 0.11 & 0.11 & 0.11 & 0.11 \\
$C_{22}$ & 0.11 & 0.11 & 0.11 & 0.11 & 0.11 & 0.11 & 0.11 & 0.11 \\
$C_{23}$ & 0.11 & 0.11 & 0.11 & 0.11 & 0.11 & 0.10 & 0.10 & 0.10 \\
$C_{31}$ & 0.18 & 0.18 & 0.18 & 0.18 & 0.18 & 0.18 & 0.17 & 0.18 \\
$C_{32}$ & 0.16 & 0.16 & 0.16 & 0.16 & 0.16 & 0.15 & 0.16 & 0.15 \\
\hline
\end{tabular}




\section{References}

1. Liu, C.H.; Huang, P.H. Managing Driver Stress in Coach Tourism. In Proceedings of the Global Business Future Trends, National Kaohsiung University of Science and Technology, Kaohsiung City, Taiwan, 22 June 2018; Available online: http://tm.kuas.edu.tw/2017\%e5\%95\%86\%e6\%a5\%ad\%e7\%8f\%be\%e4\%bb\%a3\%e5\%8c\% 96\%е5\%ad\%b8\%е8\%a1\%93\%e7\%a0\%94\%е8\%a8\%8е\%е6\%9c\%83-\%e5\%be\%b5\%е7\%a8\%bf\%e4\%b8\%ad/ (accessed on 2 May 2020).

2. Liu, C.H.; Tzeng, G.H.; Lee, M.H.; Tseng, H.L.; Lee, P.Y. Using a hybrid MCDM model combining Fuzzy DEMATEL Technique to examine the job stress of coach driver. In Intelligent Decision Technologies; Watada, J., Phillips-Wren, G., Jain, L.C., Howlett, R.J., Eds.; Springer: Berlin/Heidelberg, Germany, 2012; Volume 2, pp. 149-156.

3. Liu, C.H.; Mo, K.O.; Lee, Y.C. Managing job stress of Taiwanese coach driver-the revelation of the cognitive coping strategy. J. Dev. Prospect. 2019, 26, 93-122.

4. Liu, C.H.; Lee, M.H.; Wang, S.H.; Lin, Y.H. Factors of Coach Driver Job Stress in Taiwan. In Proceedings of the Asia Pacific Tourism Association (APTA), Taipei, Taiwan, 26-29 June 2012.

5. Kao, H.T.; Hsieh, H.S.; Chen, C.H. The study on the relationship between driving safety perception and aberrant driving behavior for tourist bus drivers. J. Taiwan Hosp. Tour. Spec. Issue Asia Tour. Forum Proc. 2010, 7, 133-144.

6. Dewe, P.J.; O'Driscoll, M.P.; Cooper, C.L. Theories of psychological stress at work. In Handbook of Occupational Health and Wellness; Gatchel, R.J., Schultz, I.Z., Eds.; Springer: Berlin, Germany, 2012; p. 23. [CrossRef]

7. Lazarus, R.S.; Folkman, S. Stress, Appraisal and Coping; Springer: New York, NY, USA, 1984.

8. Cranwell-Ward, J.C. Thriving on Stress; Routledge: London, UK, 1993.

9. Tung, M.H. Sources of occupational stress in your bus's driver. J. Chin. Inst. Transp. 2016, 28, $187-211$.

10. Becken, S. Towards sustainable tourism transport: An analysis of coach tourism in New Zealand. Tour. Geogr. 2005, 7, 23-42. [CrossRef]

11. Wang, H.; Mob, X.; Wang, Y.; Liu, R.; Qiu, P.; Dai, J. Assessing Chinese coach drivers' fitness to drive: The development of a toolkit based on cognition measurements. Accid. Anal. Prev. 2016, 95, 395-404. [CrossRef]

12. Paul, D.; Lumsdon, L. The determinants of gay excursion coach travel: A qualitative marketing analysis. Serv. Ind. J. 1999, 19, 158-168.

13. Zhu, B.W.; Zhang, J.R.; Tzeng, G.H.; Huang, S.L.; Xiong, L. Public open space development for elderly people by using the DANP-V model to stablish continuous improvement strategies towards a sustainable, healthy aging society. Sustainability 2017, 9, 420. [CrossRef]

14. CMI. Coach. Primedia Bus. Mag. Media 2013, 96.

15. Lue, C.C.; Crompton, J.L.; Fesenmaier, D.R. Conceptualisation of multidestination pleasure trips. Ann. Tour. Res. 1993, 20, 289-301. [CrossRef]

16. Enoch, Y. Contents of tour packages. A cross-cultural comparison. Ann. Tour. Manag. 1996, 23, 599-616. [CrossRef]

17. Quiroga, I. Characteristics of package tours in Europe. Ann. Tour. Res. 1990, 17, 185-207. [CrossRef]

18. Baloglu, S.; Shoemaker, S. Prediction of senior travelers' motorcoach use from demographic, psychological, and psychographic characteristics. J. Travel Res. 2001, 40, 12-18. [CrossRef]

19. Huang, P.H. Job Stressors, Cognitive Appraisal and Stress Outcomes. Master's Thesis, Chinese Culture University, Taipei City, Taiwan, 2017.

20. Kaplan, H. Themes, lacunae and directions in research on psychological stress. In Psychosocial Stress: Perspectives on Structure, Theory, Life Courses and Methods; Kaplan, H., Ed.; Academic: New York, NY, USA, 1996; pp. 369-401.

21. Cooper, C.L.; Dewe, P.; O’Driscoll, M. Organizational Stress: A Review and Critique of Theory, Research, and Applications; Sage: Thousand Oaks, CA, USA, 2001.

22. Selye, H. Stress without Distress; Lippincott: Philadelphia, PA, USA, 1974.

23. Greenberg, S.F. Stress and the Teaching Profession; Paul H. Brookes: London, UK, 1984.

24. Wong, S.C.; Huang, C.Y. A Factor-Cluster Approach to understanding Hong Kong hotel employees' symptom-management related coping behavior towards job stress. Asia Pac. J. Tour. Res. 2014, 19, 469-491. [CrossRef] 
25. EFILW (European Foundation for the Improvement of Living and Working Conditions) Home Page. 2010. Available online: https://www.eurofound.europa.eu/publications?ef_search=job+stress\&field_ef_document _type_tid=All\&published_at=pdf (accessed on 21 April 2020).

26. Kompier, M.A.J. Bus Drivers: Occupational Stress and Stress Prevention. Available online: https://www.ilo. org/wcmsp5/groups/public/---ed_protect/---protrav/---safework/documents/publication/wcms_250105.pdf (accessed on 2 May 2020).

27. Cooper, C.L.; Marshall, J. Occupational sources of stress: A review of the literature relating to coronary heart disease and mental ill health. J. Occup. Psychol. 1976, 49, 11-28. [CrossRef]

28. Smylie, M.A. Teacher stress in a time of reform. In Understanding and Preventing Teacher Burnout; Vendenberghe, R., Huberman, M.A., Eds.; Cambridge University Press: Cambridge, UK, 1999.

29. Hu, H.H.; Cheng, C.W. Job stress, coping strategies, and burnout among hotel industry supervisors in Taiwan. Int. J. Hum. Resour. Manag. 2010, 21, 1337-1350.

30. Carver, C.S.; Schier, M.F. Stress, coping and self-regulatory. In Handbook of Personality Theory and Research; Lawrence, A.P., Olive, P.J., Eds.; The Guilford Press: New York, NY, USA, 1999.

31. Lazarus, R.S. Little hassles can be hazardous to health. Psychol. Today 1981, 15, 58-62.

32. Lazarus, R.S. The stress and copping paradigm. In Models for Clinical Psychology; Eisdorfer, C., Cohen, D., Maxim, K.P., Eds.; MTP Press: Lancaster, UK, 1981.

33. Lazarus, R.S.; Cohen, J.B.; Folkman, S.; Kanner, A.; Schaefer, C. Psychological stress and adaptation; some unresolved issues. In Selye's Guide to Stress Research; Selye, H., Ed.; Van Nostrand Reinhold: New York, NY, USA, 1980; Volume 1.

34. Fisher, S. Stress and Strategy; Lawrence Erlbaum Associates: London, UK, 1986.

35. Lazarus, R.S. Stress and Emotion: A New Synthesis; Springer Publishing Co: New York, NY, US, 1999.

36. Shinn, M.; Rosario, M.; Morch, H.; Chestnut, D.E. Coping with stress and burnout in the human services. J. Personal. Soc. Psychol. 1984, 46, 864-876. [CrossRef]

37. Latack, J.C. Coping with job stress: Measures and future directions for scale development. J. Appl. Psychol. 1986, 71, 377-385. [CrossRef]

38. Lin, Y.L.; Lu, L.; Lu, C.Q. The association between interpersonal stress and job satisfaction and employees' health: Chinese coping strategies. Int. J. Commer. 2014, 6, 57-72.

39. Saaty, T.L. Decision Making with Dependence and Feedback: The Analytic Network Process; RWS Publications: Pittsburgh, PA, USA, 1996.

40. Tzeng, G.H.; Huang, C.Y. Combined DEMATEL technique with hybrid MCDM methods for creating the aspired intelligent global manufacturing \& logistics systems. Ann. Oper. Res. 2012, 197, 159-190.

41. Liu, C.H. Schemes for enhancing Taiwanese cruise PAK relationships using the hybrid MADM model. Tour. Manag. 2018, 69, 510-522. [CrossRef]

42. Tzeng, G.H.; Huang, J.J. Multiple Attribute Decision Making: Methods and Applications; Taylor \& Francis Group: New York, NY, USA, 2011.

43. Yang, J.L.; Tzeng, G.H. An integrated MCDM technique combined with DEMATEL for a novel cluster-weighted with ANP method. Expert Syst. Appl. 2011, 38, 1417-1424. [CrossRef]

44. Liu, C.H.; Tzeng, G.H.; Lee, M.H. Strategies for improving cruise product sales in the travel agency-Using hybrid MCDM models. Serv. Ind. J. 2013. [CrossRef]

45. Lu, I.Y.; Kuo, T.; Lin, T.S.; Tzeng, G.H.; Huang, S.L. Multicriteria decision analysis to develop effective sustainable development strategies for enhancing competitive advantages: Case of the TFT-LCD industry in Taiwan. Sustainability 2016, 8, 646. [CrossRef]

46. Opricovic, S.; Tzeng, G.H. Multicriteria planning of post-earthquake sustainable reconstruction. Comput.-Aided Civ. Infrastruct. Eng. 2002, 17, 211-220. [CrossRef]

47. Liu, C.H.; Tzeng, G.H.; Lee, M.H. Improving tourism policy implementation-The use of hybrid MCDM models. Tour. Manag. 2012, 33, 413-426. [CrossRef]

48. Opricovic, S.; Tzeng, G.H. Fuzzy Multicriteria Model for Post-Earthquake Land-Use Planning. Nat. Hazards Rev. 2003, 4, 59-64. [CrossRef]

49. Opricovic, S.; Tzeng, G.H. Compromise solution by MCDM methods: A comparative analysis of VIKOR and TOPSIS. Eur. J. Oper. Res. 2004, 156, 445-455. [CrossRef]

50. Opricovic, S.; Tzeng, G.H. Extended VIKOR method in comparison with outranking methods. Eur. J. Oper. Res. 2007, 178, 514-529. [CrossRef] 
51. Devellis, R. Scale Development Theory and Applications; Sage Publications: New York, NY, USA, 2012.

52. Faugier, J.; Sargeant, M. Sampling hard to reach populations. J. Adv. Nurs. 1997, 26, 790-797. [CrossRef]

53. Directorate General of Highway, MOC. Coach Driver Training Kit. 2018. Available online: https://www.thb.gov.tw/sites/ch/modules/download/download_list?node=ab6360d5-f1c6-4017-a72 4-b6344f14474b\&c=74e05737-7847-4162-8a21-708bec63a091 (accessed on 22 July 2018).

54. China Times. No Chinese Mainland Tourists, Coach Sector is Going Bankruptcy. Available online: https://www.chinatimes.com/realtimenews/20160505002609-260409?chdtv (accessed on 25 April 2020).

55. Dewe, P.; Cooper, C. Occupational stress and work: From theory to intervention. In Positive Human Functioning from a Multidimensional Perspective; Gomes, R., Resende, R., Alboquerque, A., Eds.; Nova Science Publications Inc.: New York, NY, USA, 2014; pp. 5-35.

56. Travel Rich. Forum of Travel Industry Development-Session of Transportation/Coach. 2017. Available online: https://b2b.richmarcom.com.tw/newweb/news_into.aspx?Second_classification_id=3\&Subject_id= 24010 (accessed on 21 April 2020).

(C) 2020 by the author. Licensee MDPI, Basel, Switzerland. This article is an open access article distributed under the terms and conditions of the Creative Commons Attribution (CC BY) license (http://creativecommons.org/licenses/by/4.0/). 